\title{
Happy holidays from the editors of Pediatric Nephrology
}

\author{
Otto Mehls • Michel Baum
}

Published online: 21 November 2008

(C) IPNA 2008

Dear Friends and Colleagues,

On behalf of the editorial staff and Springer, we would like to wish the members of IPNA, our readers, contributors, and all of their families a happy holiday season and a joyous New Year. It has been a wonderful year for our Journal, and we have immensely enjoyed the privilege of helping to provide our readers with the latest scientific developments in pediatric nephrology. We could not have accomplished this without our contributors as well as our devoted editorial board and reviewers who helped us evaluate over 600 manuscripts last year. We are indebted to all of you, and we are deeply appreciative of your hard work.

We would like to take this opportunity to mention the excellent support of our assistant editors, Uri Alon, Raymond Quigley, Franz Schaefer, and Burkhard Tönshoff whose terms will end within 2009. These assistant editors have provided invaluable assistance in handling manuscript

O. Mehls

Division of Pediatric Nephrology, University Children's Hospital, Im Neuenheimer Feld 150,

69120 Heidelberg, Germany

M. Baum ( $\square)$

Division of Pediatric Nephrology, University of Texas

Southwestern Medical Center,

5323 Harry Hines Boulevard,

Dallas, TX 75390-9063, USA

e-mail: michel.baum@utsouthwestern.edu reviews, resolving conflicting reviewer evaluations and advising on invited reviews and commentaries.

Over the next year we will continue our policy of publishing excellent reviews and editorial commentaries that will keep us abreast of the latest advances in our field. The success of our educational mission in past years could not have been met without our teaching editors Willem Proesmans, Howard Trachtman, and Robert Mak and the large number of authors who have contributed articles. We are indebted to you all.

We hope that you will contact us if you have any suggestions for improving Pediatric Nephrology for our aim is that your Journal will be even better in the future. The policy of publishing teaching articles open choice will continue next year so that everyone will have access to the full journal article on line, and we will be publishing two teaching articles per issue. Patrick Niaudet will join our editorial team in 2009 as an associate editor for reviews. He will no doubt increase the breadth of our invited review articles. The new IPNA web site will be completed within the next few months. This site will be directly linked to the Journal and enhance the educational mission of both our Journal and IPNA.

As we begin a new year, we hope that you have a wonderful holiday season and wish you and your family health and happiness.

Seasons Greetings, Otto Mehls and Michel Baum Editors 